\title{
Filigrane
}

Écoutes psychothérapiques

\section{Le corps. Sur le divan, dans le fauteuil}

\section{Hélène Richard}

Volume 18, numéro 1, printemps 2009

Le corps. Sur le divan. Dans le fauteuil I

URI : https://id.erudit.org/iderudit/037716ar

DOI : https://doi.org/10.7202/037716ar

Aller au sommaire du numéro

Éditeur(s)

Revue Santé mentale au Québec

ISSN

1192-1412 (imprimé)

1911-4656 (numérique)

Découvrir la revue

Citer ce document

Richard, H. (2009). Le corps. Sur le divan, dans le fauteuil. Filigrane, 18(1), 5-6. https://doi.org/10.7202/037716ar d'utilisation que vous pouvez consulter en ligne.

https://apropos.erudit.org/fr/usagers/politique-dutilisation/ 


\title{
Le corps. Sur le divan, dans le fauteuil
}

\author{
hélène richard
}

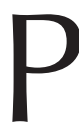

our sa dix-huitième année de parution, Filigrane a voulu consacrer ses deux dossiers à l'étude du corps, dans le contexte de l'espace transférocontretransférentiel. Non le corps de la médecine ou de la psychosomatique, mais celui porteur de messages, lieu d'inscriptions, de subjectivation et d'enchâssement d'une parole. La psychanalyse parle peu de la réalité du corps dans le contexte du travail clinique. Aux étudiants de la «talking cure», on recommande, par exemple, de n'interpréter que ce qui s'y dit verbalement. Le clinicien et son patient: de purs esprits? Dans l'intimité de la rencontre clinique, les corps des deux protagonistes témoignent pourtant de leur réalité charnelle par un langage fait, entre autres, d'odeurs, de borborygmes, de sueur, de tensions musculaires. Ce langage peut-il constituer un message à l'autre ? Habituellement, le clinicien considère inopinées les manifestations perceptibles de son corps, les jugeant comme une transgression de son idéal de neutralité bienveillante. Pourtant, y a-t-il moins neutre que le corps bien soigné ou non, parfumé à la nicotine, à l'eau de toilette ou non, hâlé ou blême, d'un clinicien/d'une clinicienne, portant des vêtements seyants ou fripés, une nouvelle coiffure, une tête grise, des cheveux teints? De quel corps s'occupe donc la psychanalyse ? Que cache et dévoile, à notre «corps défendant », cet étrange corps à corps de deux adultes sexués?

Dans ce premier dossier, les auteurs de Filigrane ont répondu à ce questionnement de la manière suivante.

Alain Lebel offre une contribution aux réflexions sur le passage du somatique au psychique. À partir de points de vue fournis par la théorie psychanalytique, par l'observation du bébé selon la méthode d'Esther Bick et par la pratique de la pédopsychiatrie, l'auteur étudie l'articulation entre les identifications primaires et secondaires qui signent l'influence déterminante des éprouvés corporels infantiles sur l'activité de représentation tout au cours de la vie. Des exemples cliniques permettent de considérer les aléas de certains états primitifs du développement physique et psychique et ainsi de mieux saisir comment se mettent en place les articulations entre psyché et soma, les défauts qui peuvent en découler et faire l'objet d'un travail au cours du processus analytique.

Pour Louise Cuddihy, la pratique de la psychanalyse met l'analyste en contact avec son propre corps, touché par ce qui vient du corps de l'analysant. Celui-ci s'adresse à l'analyste en parlant de son corps, à partir de son corps. Réfléchissant sur quelques évocations cliniques, l'auteure se demande ce qui se passe entre 
Filigrane, printemps 2009

l'analysant et l'analyste, quand le corps impose sa présence chez l'un comme chez l'autre, cela sans égard à l'organisation psychique qui prévaut chez l'analysant. Explorant alors le rapport entre le corps et la parole, elle s'interroge sur la façon d'aborder cliniquement ces différentes situations. Elle insiste, en conclusion, sur l'importance d'accéder à la parole comme issue à l'emprisonnement dans le corps, tout en précisant de quelle parole il s'agit.

Prado de Oliveira, lui, utilise la problématique du corps dans un contexte particulier, soit pour présenter sa notion de la transmission psychanalytique. Pour lui, en tant que professeur, la transmission de la psychanalyse et de sa psychopathologie doit évoquer chez l'étudiant les tensions entre rêverie et rigueur, entre idéal et réalité, toujours basées sur l'expérience clinique la plus ardue et constante. La transmission de la psychanalyse, idéalement, devrait écarter toute langue de bois. Malheureusement, l'existence de groupes et leur institutionnalisation exigent et imposent les jargons à travers lesquels les psychanalystes croient se reconnaître. Cette transmission évoquant les tensions entre rêverie et rigueur, l'auteur tentera de l'illustrer en parlant de ce que comprend la psychanalyse du corps et de sa souffrance.

Enfin, c'est à une ébauche d'exégèse que nous convie Villemaire Paquin. En effet, à partir de 1920, une impasse clinique et théorique confronte la psychanalyse. Elle amène Freud à redéfinir l'inconscient et à élaborer la deuxième topique, poursuivant ainsi la voie de la représentation. Reich, de son côté, en 1934, court-circuite l'appareil psychique et centre sa démarche sur l'énergie, ouvrant la voie du corps. L'impasse, dans un cas comme dans l'autre, ne sera pas pour autant levée dans l'immédiat. Deux vignettes, reliées par l'expression «lecture du corps », présentent un parcours sous l'éclairage de la psychanalyse contemporaine, du corps écrit, objet d'une lecture, au corps lecteur, sujet de la lecture.

Le comité de rédaction 